\title{
Current distribution data for the red-listed species of aphyllophoroid fungi in Ukraine
}

\author{
Mariia V. SHEVCHENKO (D), Vasyl P. HELUTA (D), Mariia O. ZYKOVA iD, Vera P. HAYOVA* (D) \\ M.G. Kholodny Institute of Botany, National Academy of Sciences of Ukraine, 2 Tereschenkivska Str., Kyiv 01601, Ukraine
}

\begin{abstract}
The article provides current information on distribution patterns of six species of aphyllophoroid fungi (Agaricomycetes, Basidiomycota) listed in the Red Data Book of Ukraine: Clavariadelphus pistillaris, Gomphus clavatus, Hericium coralloides, Picipes rhizophilus, Polyporus umbellatus, and Sparassis crispa. Altogether, about 500 occurrences of the fungal fruitbodies in the country are reported. Of them, over 410 recent observations have been added to those published in the Red Data Book of Ukraine in 2009. Majority of that data has been provided over the last few years via mushroom citizen science, i.e. involvement of volunteers in collecting distribution data for macrofungi with large and distinctive fruitbodies. Only specialist-verified observations were included in the datasets reported in the article. The compiled data will serve as a considerably improved basis for future re-assessments of the conservation status of these threatened species for the next edition of the Red Data Book of Ukraine.
\end{abstract}

Keywords: distribution, fungal conservation, Gomphales, mushroom citizen science, Polyporales, Red Data Book of Ukraine, threatened species

Article history. Submitted 11 November 2020. Revised 16 February 2021. Published 28 February 2021

Citation: Shevchenko M.V., Heluta V.P., Zykova M.O., Hayova V.P. 2021. Current distribution data for the red-listed species of aphyllophoroid fungi in Ukraine. Ukrainian Botanical Journal, 78(1): 47-61. https://doi.org/10.15407/ ukrbotj78.01.047

*Corresponding author (e-mail: v.hayova@gmail.com)

\section{Introduction}

Aphyllophoroid fungi (Agaricomycetes, Basidiomycota), both decomposers and mycorrhizal symbionts, are essential component of forest ecosystems. Woodinhabiting macrofungi that are capable of decomposing dead wood play a vital role in recycling processes. Furthermore, wood-decay fungi as well as litter saprobionts provide a variety of viable habitats for turnover of various biodiversity elements. Thus, maintaining diversity of aphyllophoroid fungi is crucial for ecosystem functioning.

Fungal conservation requires sufficient knowledge on the occurrence and species-specific distribution patterns of the fungi. Although there are many gaps in the knowledge on distribution and other limitations for fungal red-listing, an increased number of aphyllophoroid fungi, including those reported in this article, has been red-listed nationally and internationally over recent years (http://iucn.ekoo.se/iucn/species_list/).

In the third edition of the Red Data Book of Ukraine (2009), eight species of aphyllophoroid fungi are listed: Clavariadelphus pistillaris (L.) Donk, Fomitopsis officinalis (Batsch) Bondartsev \& Singer (as Laricifomes officinalis (Vill.) Kotl. \& Pouzar), Grifola frondosa (Dicks.) Gray, Gomphus clavatus (Pers.) Gray, Hericium coralloides (Scop.) Pers., Picipes rhizophilus (Pat.) J.L. Zhou \& B.K. Cui, in Zhou, Zhu, Chen \& Cui (as Polyporus rhizophilus Pat.), Polyporus umbellatus (Pers.) Fr., and Sparassis crispa (Wulfen) Fr. For each species, a distribution map was provided as derived from bibliographic sources, herbarium and personal data available by that time.

Over the past decade, information on the occurrence of these rather well-known and conspicuous macrofungi has significantly expanded. In addition to previously

\footnotetext{
(C) 2021 M.V. Shevchenko, V.P. Heluta, M.O. Zykova, V.P. Hayova. Published by the M.G. Kholodny Institute of Botany, NAS of Ukraine. This is an open access article under the terms of the Creative Commons Attribution License (http://creativecommons.org/licenses/by/4.0/), which permits use, distribution, and reproduction in any medium, provided the original work is properly cited
} 
documented localities, novel published records were made freely available online as well as those unpublished were communicated, particularly through the citizen science websites. Indeed, the major drivers of the recent fungal findings were intensive observation efforts made by enthusiastic amateurs under the guidance of professional mycologists, including the authors of this article. Thus, using information updated on a continuous basis, one of the above mentioned species, Grifola frondosa, listed in the Red Data Book of Ukraine as Vulnerable (VU), has been recently re-assessed and recommended to be assigned to a higher threat category, i.e. Endangered (EN) (Shevchenko et al., 2019). Another species, Fomitopsis officinalis, most probably was erroneously recorded in the country; thus, because of highly doubtful historical data and unconfirmed species occurrence, it was proposed to be excluded from the Red Data Book of Ukraine (Hayova et al., 2020).

This article contributes to distribution data for the other six nationally red-listed species of aphyllophoroid fungi in Ukraine: C. pistillaris, G. clavatus, H. coralloides, Pi. rhizophilus, Po. umbellatus, and S. crispa. Updated information on the occurrence of these fungi in the country is particularly important for re-assessment of the species for the next edition of the Red Data Book of Ukraine that is currently under preparation.

\section{Materials and methods}

Various sources of information on distribution data for each species were analysed. As a primary data source, we used label locality data on the specimens deposited in the Fungarium (KW-M) at the National Herbarium of Ukraine $(\mathrm{KW})$ as well as relevant published data obtained from literature reports. For historical records, taxonomic names and administrative units were checked and updated where necessary.

Apart from herbarium materials and bibliographic data, additional information on fungal occurrence was considered and, if appropriate, taken into account. Since the selected species are red-listed, i.e. protected by law in Ukraine, their unauthourised sampling and/or collecting fruitbodies in the country are strictly prohibited. Therefore a list of records for each species is largely based on a dataset derived from observational field research. Different field work methods of collecting data through observations were used. Some records resulted from traditional surveys of fungal diversity or mycological inventories carried out in nature conservation areas by professional mycologists, in particular by staff members of the Department of Mycology at the M.G. Kholodny Institute of Botany, National Academy of Sciences of Ukraine. However, significant portions of the datasets were compiled on a basis of unpublished results of random observations made by amateurs and reported through two social network groups (https://www.facebook. com/groups/Hryby.Ukrayiny/?ref=bookmarks, https:// www.facebook.com/groups/119266158163241/). These observation reports were only accepted by experts after verification, if a record was confirmed by one or several good quality digital images of the fungus in its natural habitat, with locality data and date of observation. Thus for each validated record, several levels of site names in the region are indicated, including municipality, village or nature conservation area and, wherever possible, specific location, followed by date, or date interval, and full name of the person. For published records, publication references are provided. Exact locality data and georeference information are omitted in the article due to data access restrictions for the red-listed species.

\section{Results}

For six species of aphyllophoroid fungi listed in the Red Data Book of Ukraine (2009), all known up to now records in Ukraine, from historical to the most recent ones, are reported. Of them, over 410 additional observations are dated within 2009-2020. Thus, including the previously known sites published in 2009, a total of about 500 occurrences are provided below.

Fungal species and administrative units (regions and districts) are arranged alphabetically.

Clavariadelphus pistillaris (L.) Donk, Meded. Bot. Mus. Herb. Rijks Univ. Utrecht 9: 72.1933 (Fig. 1, A)

This is a litter fungus rarely occurring in deciduous and mixed forests, preferably in beech forests. In the distribution map provided in the Red Data Book of Ukraine (2009), 12 sites were indicated. Since then, at least 20 new occurrences of the species have been reported. Thus at present, records of $C$. pistillaris are also known from three more regions, Chernivtsi, IvanoFrankivsk, and Khmelnytskyi. As can be seen from the list below, most frequently its fruitbodies were observed in forest habitats in Hutsulshchyna National Nature Park (Ivano-Frankivsk Region). In four regions (Chernihiv, Kyiv, Sumy, and Ternopil), historical bibliographic reports dated back to the late $19^{\text {th }}$ - early $20^{\text {th }}$ centuries were not confirmed thereafter.

Ukrainian Botanical Journal, 2021, 78(1) 

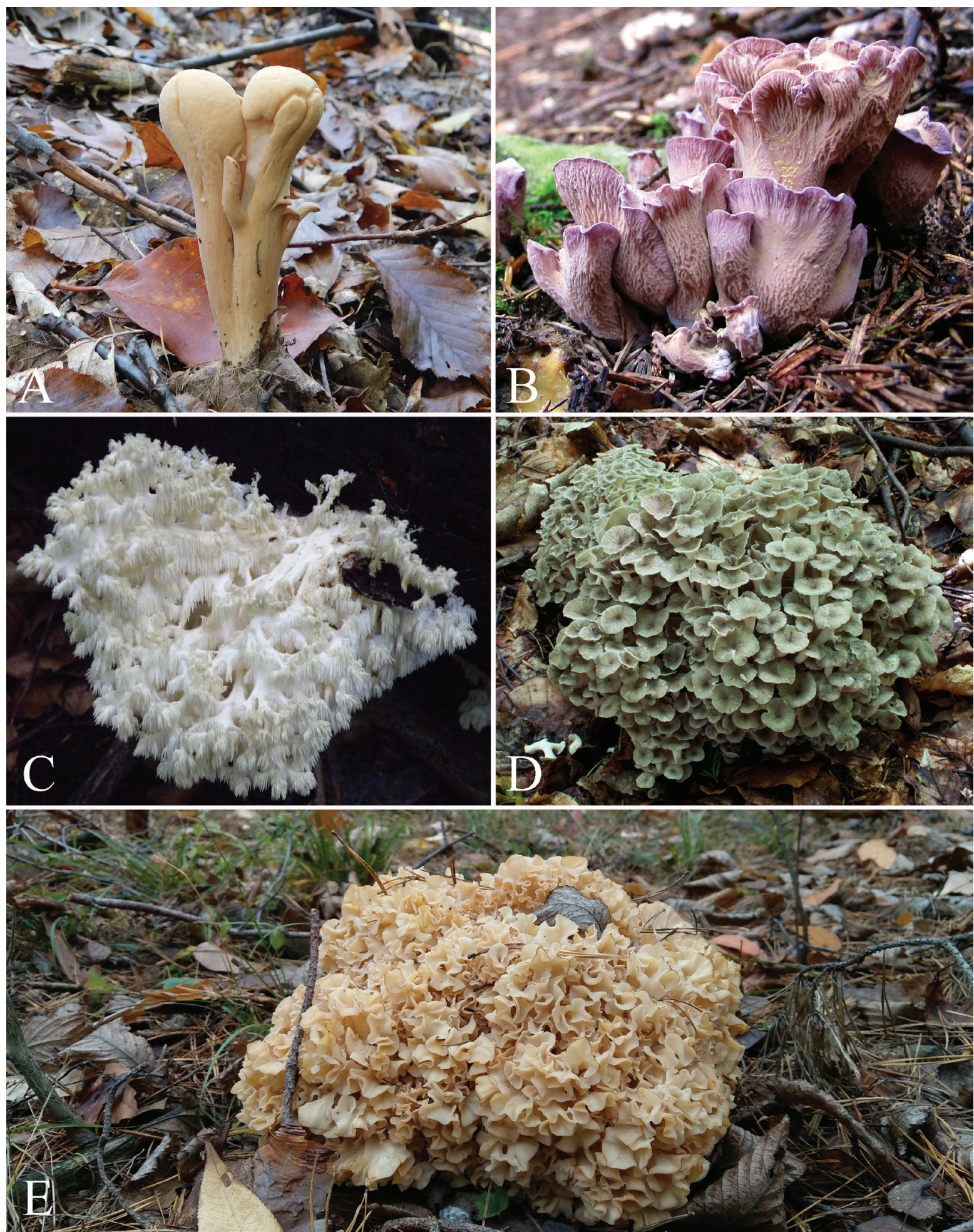

Fig. 1. Fruitbodies of the red-listed aphyllophoroid fungi in Ukraine. A: Clavariadelphus pistillaris (photo by O. Volutsa). B: Gomphus clavatus (photo by S. Kozlan). C: Hericium coralloides (photo by O. Volutsa). D: Polyporus umbellatus (photo by O. Lozovyi). E: Sparassis crispa (photo by O. Zykov) 


\section{Distribution in Ukraine}

Autonomous Republic of Crimea: Simferopol District, Angarskyi Pass, Angar-Butun forest parcel, 11.09.2002, 21.09.2002, I. Sarkina (Sarkina et al., 2003); Yalta municipality, Nikita, Nikita Botanical Garden, Cape Martian Nature Reserve, 04.03.1999, I. Sarkina (Sarkina et al., 2003).

Cherkasy Region: Kaniv District, Kaniv Nature Reserve (Usichenko et al., 2005; Prudenko, Dzhagan, 2008).

Chernihiv Region: Sosnytsia District, Sosnytsia settlement (Borščow, 1869).

Chernivtsi Region: Chernivtsi District, Kulykivka village, 18.10.2020, O. Volutsa.

Ivano-Frankivsk Region: Bohorodchany District, Hrabovets village, 26.08.2006, V. Malanyuk (Malanyuk, 2019); Kosiv District, Hutsulshchyna National Nature Park, Sheshory village, 12.09.2013, V. Heluta; Holytsia ridge, 02.10.2010, 18.10.2014, October 2016-2017, 17.08.2018, L. Derzhypilskyi; Yablunivka forestry, September 2012, L. Derzhypilskyi, S. Fokshei; Kamenystyi ridge, Gregit mountain, Mykhalkova mountain, 18.08.2010, L. Derzhypilskyi (Fokshei, 2016, 2019); ibid., 11.09.2013, L. Derzhypilskyi, S. Fokshei, V. Heluta; Yaremche District, Tatariv village, 28.08.2020, M. Osadchyi.

Kharkiv Region: Zmiiv District, Korobiv Khutir village, Homilshanski Lisy National Nature Park, 03.11.2002, D. Leontyev (Akulov, Leontyev, 2008; Usichenko, 2011).

Khmelnytskyi Region: Dunaivtsi District, Makiv village, 11.08.2019, O. Nedokushev; Yarmolyntsi District, Yarmolyntsi settlement, 25.10.2020, O. Nevstruyeva.

Kyiv city: Kyiv, 30.10.2020, N. Volosatova.

Kyiv Region: Irpin (Girzitska, 1929).

Lviv Region: Lviv city, Sukhiv, 30.08.1968 (Dudka, 2008); Pustomyty District, Hryniv village, 26.09.2017, O. Sharabura.

Sumy Region: Krolevets District, Krolevets town (Borščow, 1869).

Ternopil Region: Zalishchyky District, Zalishchyky town, 12.09.1918 (Wróblewski, 1922).

Transcarpathian Region: Mizhhirya District, Synevyr National Nature Park, 21.08.2017, T. Niroda (Tyukh, Niroda, 2019); Rakhiv District, Svydovets mountain range, Kuziy massif, August 1933 (Pilát, 1940); Carpathian Biosphere Reserve, Marmarosh massif (Gleb et al., 2016); Rakhiv town, 20.09.2017, V. Nebela; Svalyava, 23.10.2020, V. Rudenko; Tyachiv District (Rekita, 2014).
Gomphus clavatus (Pers.) Gray, Nat. Arr. Brit. Pl. (London) 1: 638. 1821 (Fig. 1, B)

This species is known as a rare fungus forming mycorrhiza with coniferous trees and beech in mature and old growth forests on calcareous and loamy soils (limestone, chalk, marl, etc.). Apart from a single locality near Kyiv city (Zerova et al., 1972) referred to in the Red Data Book of Ukraine (2009), 20 more observations have been reported for this species during the past decade. In general, our knowledge on its distribution has expanded to include three western administrative units - Chernivtsi, Ivano-Frankivsk, and Transcarpathian regions, as well as another recent record in Kyiv Region. The greatest number of occurrences (14) for G. clavatus is currently known from Ivano-Frankivsk Region.

\section{Distribution in Ukraine}

Chernivtsi Region: Vyzhnytsia District, Shurdyn pass, 21.08.2016, S. Kozlan.

Ivano-Frankivsk Region: Kosiv District, Hutsulshchyna National Nature Park, Kramy mountain meadow, 31.07.2014, 05.08.2015, S. Fokshei, O. Pohribnyi (Fokshei, 2016, 2019); Bania Bereziv village, 12.08.2019, V. Basaraba; Sheshory village, 20.07.2019, Y. Myzerniuk; Kosiv town, 08.07.2014, O. Zykov; ibid., 25.07.2019, Ye. Rudenko; Nadvirna District, Gorgany Nature Reserve, Bystrytsia village, 06.08.2011, V. Malanyuk (Malanyuk, 2012, 2019); Deliatyn settlement, Klyvskyi Botanical Reserve, 09.09.2008, V. Malanyuk (Malanyuk, 2019); Verkhovyna District, Verkhovynskyi National Nature Park, Perkalab village, 19.08.2013, V. Malanyuk (Malanyuk, 2019); Bukovets village, 02.09.2018, 09.08.2019, S. Kozlan; Staishche village, 28.08.2015, Bila Kobyla mountain, 19.08.2018, T. Danchuk; Verkhovyna settlement, early July 2016, T. Horelova; ibid., 19.07.2020, Kh. Zubyuk.

Kyiv city (Zerova et al., 1972).

Kyiv Region: Poliske District, Radynka village, 07.07.2018, M. Zykova (KW-M71263).

Transcarpathian Region: Mizhhirya District, Pylypets village, August 2014, Yu. Bengus (Bengus, 2016); Rakhiv District, Chorna Tysa village, 26.08.2016, K. Fedorova; Carpathian Biosphere Reserve, Chornohirsky massif, Kozmeshchyk forest parcel, 06.09.2017, R. Gleb (Antosyak et al., 2019); Lazeshchyna village, 08.09.2017, R. Gleb.

Hericium coralloides (Scop.) Pers., Neues Mag. Bot. 1: 109.1794 (Fig. 1, C)

This saprobic fungus causing white rot of wood can be most frequently found on large fallen trunks, as well 
as dead standing trunks, of Fagus spp. and Quercus spp. Hericium coralloides is known as an indicator of old growth forests; moreover, due to attractive fruitbodies it is often used as a flagship species in fungal conservation. In the Red Data Book of Ukraine (2009), H. coralloides is listed as a Vulnerable species; in total, 24 sites are depicted in the distribution map provided therein. By now, this number increased to at least 120 sites, thus the actual number of occurrences exceeds the previously known number by about fivefold. Of them, more than a half of observations are dated by 2017-2020. The majority of all known up to now observations are located in Ivano-Frankivsk, Lviv, and Transcarpathian regions.

\section{Distribution in Ukraine}

Autonomous Republic of Crimea: Korbek village (currently Izobilne village, Alushta) (Léveillé, 1842); Izobilne forestry, middle flow of the Alma river, 05.10.1960, E. Koval (Sarkina et al., 2003); Mountain Crimea, Southern Coast of Crimea (Isikov, 2003); Alushta municipality, Crimean Nature Reserve, Central forestry, October 1936, Basman mountain, autumn 1937, S. Gutsevich (Sarkina et al., 2003); Alushta municipality, July, September, October 1987, V. Isikov; ibid., September 1989, L. Horovyi (KW-M7868); ibid., 22.09.2000, M. Prydiuk (Sarkina et al., 2003); Generalske village, 02.06.2018, Yu. Krasylenko; Feodosia municipality, Karadag Nature Reserve, Svyata mountain, 10.07.2008 (Sarkina, Mironova, 2010); Simferopol District, Chatyrdag mountain, 01.07.2001, 03.10.2001, I. Sarkina (Sarkina et al., 2003); Yalta municipality, 20.08.1988, 19.11.1989, 04.11.2000, V. Isikov; Yalta Mountain Forest Nature Reserve, Livadiya forestry, Comboplo forest parcel, 25.07.1988, I. Sarkina (Sarkina et al., 2003); Ai-Petri mountain, 13.07.1993, 19.07.1995, I. Sarkina (Sarkina et al., 2003).

Cherkasy Region: Cherkasy town, 20.10.2018, V. Lobas; Kaniv District, Kaniv Nature Reserve (Usichenko et al., 2005; Prudenko, Dzhagan, 2008); ibid., 29.10.2013, V. Shevchyk; ibid., 10.10.2014, 23.09.2015, 14.09.2017, 10.09.2018, Yu. Kulsha (Kulsha et al., 2019); Ozeryshche village, 19.10.2012, V. Gryshchenko, Ye. YablonovskaGryschenko (Kulsha et al., 2019).

Chernivtsi Region: Chernivtsi District, Kulykivka village, 17.10.2020, H. Apetri; Khotyn Disrtict, Hrynyachka village, 21.10.2019, Zh. Storozhenko; Vyzhnytsia District, Vyzhenka village, 19.06.2013, O. Volutsa; ibid., 04.08.2020, O. Shcherbata.

Dnipropetrovsk Region: Novomoskovsk District, Samarskyi forest (Taran et al., 1989).
Donetsk Region: Svyatohirsk municipality, Svyatohirsk town, 18.07.2019, N. Mykhailychenko; Slovyansk District, Svyati Hory National Nature Park (Red Data..., 2009).

Ivano-Frankivsk Region: Dolyna District, 03.10.2020, H. Kornylo; Halych District, Halych National Nature Park, Krylos village, 20.09.2010 (Malanyuk, 2012, 2013, 2019); Pukasivtsi village, 02.11.2019, H. Marunchak; Kosiv District, Hutsulshchyna National Nature Park (Malanyuk, 2012); ibid., autumn 2013 (Bisko et al., 2016); Kosiv town, 15.10.2013, 07.05.2014, 07.10.2014, Yu. Petrichuk (Petrichuk, Pasaylyuk, 2015); ibid., 09.06.2019, 17.08.2020, S. Kozlan; Sheshory village, Hutsulshchyna National Nature Park, autumn 2013 (Bisko et al., 2016); Horod village, 07.10.2014, Yu. Petrichuk (Petrichuk, Pasaylyuk, 2015); ibid., 09.06.2019, S. Kozlan; Kamenystyi ridge, September 2009-2011, 05.09.2012, 11.09.2013, September 2014, 15.07.2015, 01.10.2015, June \& September 2016, L. Derzhypilsky, S. Fokshei (Fokshei, 2019); ibid., 15.10.2013, Yu. Petrichuk, M. Pasaylyuk (Fokshei, 2019); Kosmach village, Kamenysty ridge, Ladeskul mountain, September 2005, L. Derzhypilsky (Fokshei, 2019); Mykhalkova mountain, 25.10.2010, 13.10.2011, L. Derzhypilsky, S. Fokshei (2019); Lysyna Kosmatska mountain, 01.09.2013, O. Akulov, L. Derzhypilsky (Fokshei, 2019); Kernychnyi forst parcel, 15.10.2014, October 2017, L. Derzhypilsky, S. Fokshei (Fokshei, 2019); Sokilsky ridge, October 2014, 02.07.2018, S. Fokshei (Fokshei, 2019); Yabluniv settlement, 17.06.2020, O. Soltys; Nadvirna District, 16.09.2018, T. Hrabovska; Rohatyn District, 06.11.2020, V. Stasyshyn; Voroniv village, 27.05.2017, L. Babyak; Yaremche municipality, Vorokhta settlement, 11.08.2019, V. Ilchyshyn; ibid. 27.09.2020, A. Yemchuk.

Kharkiv Region: Zmiiv District, Homilshanski Lisy National Nature Park, 02.07.2003, 19.07.2004, O. Akulov (Akulov, Leontyev, 2008; Usichenko, 2011).

Khmelnytskyi Region: Horodok District, Ivankivtsi village, 28.07.2019, V. Kydanchuk-Dronska.

Kirovohrad Region: Znamyanka District, Vodyane village, Chornoliskyi Landscape Reserve, 10.09.1977, V. Heluta, A. Bukhalo (Red Data..., 2009); ibid., 16.09.2018, Yu. Vovkotrub; ibid., 13.10.2018, O. Kyrpa.

Kyiv city: 30.05.2020, anonymous; Holosiiv District, Feofania park, 27.10.2019, S. Strybozh; Holosiiv National Nature Park, 11.11.2017, Ye. Rudenko; Kytaiv, 05.11.2017, 13.10.2018, O. Ivashchenko.

Kyiv Region: Borodyanka District, Koblytsya village, 15.11.2020, Ye. Plakhotnyuk. 
Lviv Region: Lviv city, 29.09.2017, T. Vertepny; Lviv city, Vynnyky, 25.10.2020, U. Nych; Boryslav municipality, Skhidnytsya settlement, 02.10.2020, Yu. Bykova; Brody District, Perelisky village, 20122013, V. Batochenko (Batochenko, 2019); Drohobych District, Medvezha village, 11.10.2019, I. Blyznyk; Peremyshlyany District, Sukhodil village, 23.09.2018, A. Kozak; Pustomyty District, Lypnyky village, 27.07.2019, H. Pankiv; Sambir District, Sprynya village, 04.10.2020, O. Kit; Skole District, Skolivski Beskydy National Nature Park, 07.10.2016, O. Kamarynskyi; Hrebeniv village, 09.09.1976, T. Horova (KWM2073); ibid., 15.08.1976, T. Horova (KW-M2076); Smozhe village, 12.09.1975, T. Horova (KW-M2074); Stryi District, 08.09.2020, Ya. Terletsky; 01.09.2020, I. Berezovskyi; Turka District, Verkhnye Husyne village, 12.07.2014, O.V. Babiychuk (Babiychuk, 2019); Yavoriv District, 22.09.2020, M. Holota; Domazhyr village, 20.10.2019, R. Kalyna; Roztochya Nature Reserve, 14.09.1991， 23.09.1996， 24.09.1997， 29.09.1998 (Baziuk, 2000); Roztochchya Nature Reserve, Vereshchytsia village, 11.09.2017, O. Stolyarov; Rokytne village, 12.09.2017, S. Dyomin; Stradch village, 19.09.1981 (Dudka, 2008); Zhovkva District, 12.09.2020, O. Korostynska; Rokytne village, 19.09.2017, K. Sokolov; Zarudtsi village, 08.09.2017, K. Sokolov; Zavadiv village, 27.07.2019, O. Yesipenko; Zhydachiv District,15.09.2017, 06.11.2017, 26.07.2020, Ya. Terletsky; ibid., 10.10.2020, M. Motychak; Zolochiv District, Cheremoshnya village, 09.10.2017, R. Yurechko (Yurechko, 2019); Pidhirne village, 30.09.2018, A. Servanchuk; Pobich village, 11.10.2018, V. Sapozhnyk, R. Yurechko (Yurechko, 2019); Trudovach village, 09.10.2017, R. Yurechko (Yurechko, 2019).

Mykolaiv Region: Voznesensk District, Trykraty village, 26.11.2020, O. Balahura.

Sumy Region: Krolevets District, near Krolevets town (Borščow, 1869); Trostyanets District, Trostyanets town, 25.10.2006, V. Parkhomenko (Karpenko, 2009).

Ternopil Region: Berezhany District, Berezhany town, Rai (Namysłowski, 1914); Terebovlya District, Strusiv village, mid-September 2016, O. Stolyarov.

Transcarpathian Region: Irshava District, Bilky village, 23.10.2020, S. Dudash; Khust District, Drahove village, 05.10.2019, M. Popadynets; Mizhhirya District, Synevyrska Polyana village, September 2019, P. Shehda; Mukachevo District, Kolchyne village, 12.10.2009, R. Bilanych; Verkhnya Vyznytsia village, 28.10.2020, M. Chusa; Rakhiv District (Pilát, 1940); Pip Ivan mountain, Berlebash, August 1937 (Pilát, 1940); near the Bilyi Potik
River, October 1935 (Pilát, 1940); near the Mokranka River, August 1932 (Pilát, 1940); Svydovets, Kuziy, August 1933 (Pilát, 1940); Kvasy village, 14.09.1954, 16.09.1954, M. Smitska; Carpathian Biosphere Reserve (Marmarosh massif), near Strungi mountain meadow, August 2016 (Akulov, 2016; Gleb et al., 2016); Petros mountain, 10.10.2010, Ye. Novosad; Perechyn District, Lumshory village, 23.07.2019, A. Zubenko; ibid., 02.08.2020, O. Khaustova; Svalyava District, Svalyava town, 01.10.2017, I. Bezvershenko; ibid., 23.10.2020, V. Rudenko; Polyana village, 17.09.2020, M. Sanytskyi; Uklyn village, 09.10.2017, V. Rudenko; Tyachiv District (Rekita, 2014), Carpathian Biosphere Reserve, Uholsko-Shyrokoluzhanskyi massif (Küffer et al., 2004); ibid., 13.06.2018, A. Kozurak; Mala Uholka village, 14.09.1976, T. Horova (KW-M2075), ibid., 23.10.2015, 25.09, 30.09.2017, R. Gleb; Uzhhorod District, Uzhhorod town, 10.09.2017, H. Ponomarenko; ibid., 15.10.2017, Y. Dub; between Nevytske and Kamianytsia villages, 26.09.2014, O. Bezsmertna; Orikhovytsya village, 12.10.2020, I. Katrych-Rusyn; Kamianytsya village, 23.09.2020, O. Khartum; Velykyi Bereznyi District, Kostryna village, Uzhansky National Nature Park, 06.09.1954, M. Smitska.

Vinnytsia Region: Vinnytsia town, Piatnychany forest, 18.11.2020, O. Hershtyn.

Volyn Region: Kovel District, Kovel town, V. Heluta (Red Data..., 2009).

Picipes rhizophilus (Pat.) J.L. Zhou \& B.K. Cui, in Zhou, Zhu, Chen \& Cui, PLoS ONE 11(8): e0159495, 16. 2016

This rare fungus inhabiting rhizomes of steppe grasses is confined to forb-bunchgrass and bunchgrass steppe communities in Ukraine. In the Red Data Book of Ukraine (2009), Picipes rhizophilus is listed under its synonymic name, Polyporus rhizophilus Pat. The largest number of occurrences of $P$. rhizophilus originates from the 1950s and 1970s, 17 and 8, respectively; most of these specimens, collected in five sites in the steppe zone (Donetsk and Luhansk regions), are deposited in the Fungarium (KW-M) at the National Herbarium of Ukraine (KW). There are only three additional records from Crimea and Luhansk Region reported in the early 2000s.

\section{Distribution in Ukraine}

Autonomous Republic of Crimea: Kazantyp Nature Reserve (Sarkina, 2008); Opuk Nature Reserve, July 2002 (Sarkina, 2004); Southern Coast of Crimea (Sarkina, 2008). 
Donetsk Region: Nikolske District, Ukrainian Steppe Nature Reserve, Kamyani Mohyly branch, 01.06.1954, 03.09.1954, O. Boychuk (KW-M18449, KW-M18450); ibid., 09.05.1955, I.N. Kolesnyk (KW-M18446); Novoazovsk District, Ukrainian Steppe Nature Reserve, Homutovskyi Step branch, 05.06.1970, I. Soldatova (KW-M18464, KW-M18465, KW-M18467); ibid., 06.06.1970 (KW-M18466) (Soldatova, 1972); ibid., 21.10.1972, I. Soldatova (KW-M18476).

Kherson Region: Chaplynka District, AskaniaNova Biosphere Reserve, 16.06.1970 (KW-M18470) (Soldatova, 1972; Wasser, Soldatova, 1977); Hola Prystan District, Chornomorskyi Biosphere Reserve, 06.06.1972 (Soldatova, 1972).

Luhansk Region: Dovzhansk District, Luhansk Nature Reserve, Provalskyi Step branch, Provallya village, 18.09.2005, M. Prydiuk (Prydiuk, 2005); Milove District, 1954, 1955, M.. Zerova (Zerova, 1956, 1957; Soldatova, 1972); Luhansk Nature Reserve, Striltsivskyi Step branch, 30.05.1955, M. Zerova (KW-M18445); ibid., 27.05.1956, 29.05.1956, 19.08.1956, 12.05.1957, 14.05.1957, 23.05.1957, 24.05.1957, 25.05.1957, 28.05.1957, Z. Sarycheva (KW-M18443, KW-M18448, KW-M18451-KW-M18457, KW-M18459); ibid., 13.05.1958, O.Dubovyk, ibid., 09.06.1956, O. Boychuk (KW-M18485); ibid., 15.05.1971 (Soldatova, 1972).

\section{Polyporus umbellatus (Pers.) Fr., Syst. Mycol.} (Lundae) 1: 354.1821 (Fig. 1, D)

This rare species develops its distinctive fruitbodies at the trunk bases or on large underground roots of Quercus spp., Fagus spp., and Carpinus spp. In Ukraine it is known to occur in oak, oak-hornbeam, and beech forests. In the distribution map presented in the Red Data Book of Ukraine (2009), 12 sites are indicated. Since then, over 130 occurrences of $P$. umbellatus have been reported from new and already known localities. Thus altogether, a total number of the records has increased more than tenfold during 2009-2020. Moreover, records of this fungus at present are known from six more regions of the country: Chernivtsi, Ivano-Frankivsk, Khmelnytskyi, Vinnytsia, Volyn, and Zhytomyr regions. Majority of the reports came from Ivano-Frankivsk Region.

\section{Distribution in Ukraine}

Autonomous Republic of Crimea: Alushta municipality, Crimean Nature Reserve, autumn 1936, S. Gutsevich (Sarkina et al., 2003); Bakhchisarai District, Bilogirsk District, Simferopol District (Sarkina et al., 2003).

Cherkasy Region: Kaniv District, Kaniv Nature Reserve, 19.06-24.07.2009, 14.06-27.07.2010,
16.06.2011, June 2012, M. Prudenko; ibid., 05.06.2014, 12.06-06.08.2015, 10.06-04.07.2016, 10.06.2017, 20.06.2018, Yu. Kulsha (Usichenko et al., 2005; Prudenko, Dzhagan, 2008; Kulsha et al., 2019); Monastyryshche District, Satanivka village (Red Data..., 2009).

Chernivtsi Region: Khotyn District, Blyshchad village, 16.08.2018, Zh. \& Yu. Storozhenko (Storozhenko, 2019); Storozhynets District, Storozhynets town, 06.09.2018, V. Kravchuk; Vyzhnytsya District, Voloka village, July 2019, N. Kostyn; Zastavna District, Rzhavyntsi village, 20.06.2019, I. Rubtsov.

Ivano-Frankivsk Region: Bohorodchany District, Hrabovets village, July 2003, V. Malanyuk (Malanyuk, 2019); Rosilna village, 15.06.2016, R. Polivchak; Halych District, Halych town, 2011-2018, V. Malanyuk (Malanyuk, 2019); Halych National Nature Park, Krylos village, June-August 2010-2012, 14.07.2011,26.08.2012, V. Malanyuk (Malanyuk, 2012; 2013, 2019); Kurypiv village, 20.06.2016, R. Polivchak; ibid., 09.07.2020, V. Khrystyuk; Vysochanka village, 19.08.2010, 26.08.2012, V. Malanyuk (Malanyuk, 2019); Kalush District, Ripyanka village, 14.07.2017, R. Polivchak; Pidmykhailya village, 07.06.2018, 02.09.2018, 21.06.2019, 15.08.2019, V. Petriv; Kolomyia District, 15.06.2019, I. Popovych; Hrushiv village, 18.06.2019, M. Marunyak; Kosiv District, near Kosiv town, 25.06.2020, S. Kozlan; Hutsulshchyna National Nature Park (Malanyuk, 2012); Lucha village, 17.06.2014, S. Fokshei (Fokshei, 2016, 2019); Verbovets village, 19.06.2014, 24.06.2014, M. Pasaylyuk (Petrichuk, Pasaylyuk, 2015); ibid., 19.06.2019, V. Tsymbalyuk; ibid., June-August 2009-2018, L. Derzhypilskyi, S. Fokshei (Fokshei, 2019); Khimchyn village, 14.06.2005, L. Derzhypilskyi; ibid., July 2011, 27.06.2015, S. Fokshei (Fokshei, 2019); ibid., 19.06.2014, Yu. Petrichuk (Petrichuk, Pasaylyuk, 2015); ibid., 07.06.2018, Z. Hostyuk (Fokshei, 2019); ibid., 04.07.2019, G. Yuriychuk; Kamenystyi ridge, September 2014, 18.06.2018, L. Derzhypilskyi (Fokshei, 2019); Luchky village, 17.06.2019, P. Kornas; Rybne village, 21.06.2019, R. Drohomyretskyi; Pistyn village, 13.07.2019, S. Kozlan; Verbovets village, 19.06.2019, V. Tsymbaliuk; Tysmenytsia District, Staryi Lysets village, 23.07.2017, V. Soychuk.

Kharkiv Region: Zmiiv District, Homilshanski Lisy National Nature Park, Haidary village, 21.06.2002, 30.06.2003, O. Akulov, D. Leontyev (Akulov, Leontyev, 2008; Usichenko, 2011); Homilshanski Lisy National Nature Park, 11.06.2018, D. Leontyev, Yu. Bengus (Prylutsky et al., 2019); Krasnokutskyi District, Slobozhansky National Nature Park, Koziivka village, 
19.06.2013, O. Prylutsky, N. Brusentsova (Brusentsova et al., 2019; Prylutsky et al., 2019).

Khmelnytskyi Region: Derazhnya District, Zharok village, 25.06.2020, P. Martyniuk; Horodok District, Sataniv town, 1936 (Bondartsev, 1953); ibid., 22.06.2019, 24.08.2019, V. Kydanchuk-Dronska; Shepetivka District, Kamyanka village, 07.07.2010, A. Kondratyuk.

Lviv Region: Lviv city, 12.06.2019, S. Hrytsyk; ibid., 30.06.2019, A. Mazurok; ibid., 01.09.2019, Y. Khmura; Mykolaiv District, 23.06.2019, O. Lupynis; Peremyshlyany District, Bibrka settlement, 01.09.2019, V. Tsepin; Pustomyty District, Tovshchiv village, 02.09.2018, A. Chukhan; Yavoriv District, Oselya village, 20.06.2020, O. Cherkes; Roztochya Nature Reserve, Stavky village, 11.07.1998, 12.09.1999 (Baziuk, 2000); Yavoriv National Nature Park, 16.08.2019, O. Ruchko; Zhovkva District, Krekhiv village, 07.06.2019, A. Blavatskyi; Zhydachiv District, Monastyrets village, 10.08.2018, R. Berezovskyi; Chertizh village, 03.07.2019, I. Berezovskyi; Zolochiv District, Verhobuzh village, 09.07.2017, 28.07.2018, R. Yurechko (Yurechko, 2019).

Sumy Region: near Sumy town, 20.06.1984 (Karpenko, 2004); ibid., 24.07.2003, O. Rodina (KW-M25456); Sumy municipality, near Bytytsia village, 15.06.1988 (Karpenko, 2004).

Ternopil Region: Berezhany District, Berezhany town, Rai (Namysłowski, 1914); ibid., 05.09.2017, O.Furdela; Buchach District, Pomirtsi village, 26.06.2018, S. Andreiv; Trybukhivtsi village, 19.06.2019, S. Andreiv; Sokoliv village, 23.06.2019, S. Andreiv; Duliby village, 07.07.2019, S. Andreiv; Terebovlya District, Strusiv village, mid-September 2016, O. Stolyarov; Zalischyky District, Lytiachi village, 08.07.2018, R. Kutyr.

Transcarpathian Region: Mukachevo District, near Berezynka village, 16.08.2020, S. Miles; Perechyn District, Tur'i Remety village, 17.06.2007, O. Lozovyi; Turichky village, 13.07.2009, O. Senchylo (Dzhagan et al., 2010); Rakhiv District, Velykyi Bychkiv settlement, 24.06.2017, R. Gleb; Rosishka village, 26.06.2017, R. Gleb; Svalyava District, 17.06.2017, A. Voronyuk; Tyachiv District, Carpathian Biosphere Reserve, Uholsko-Shyrokoluzhanskyi massif, Mala Uholka forest parcel, 01.08.2014 (Gleb, 2016; Antosyak et al., 2019); ibid., 05.07.2016, R. Gleb; Vynogradiv District, Cherna village, 18.06.2016, V. Gleba.

Vinnytsia Region: Bar District, Mankivtsi village, 12.07.2017, O. Stakhmych; Kalynivka District, Kalynivka town, 09.06.2019, Ya. Antonova; Vinnytsia District, Vinnytsia city, 30.05.2018, D. Zhyltsov;
Zhmerynka District, Novoselytsia village, 08.06.2019, I. Semeniuk.

Volyn Region: Kivertsi District, Tsumanska Pushcha National Nature Park, Berestyane village, June 2016, M. Zykova; Lutsk District, Garazdzha village, 14.07.2017, V. Revniuk.

Zhytomyr Region: Zhytomyr town, 08.08.2017,

O. Leontiuk.

Sparassis crispa (Wulfen) Fr., Syst. Mycol. (Lundae) 1: 465.1821 (Fig. 1, E)

This is a wood decay fungus growing from trunk bases or roots of old coniferous trees, most frequently pines, but occasionally of spruce and fir trees as well. Sparassis crispa is listed as Endangered in the Red Data Book of Ukraine (2009), where its distribution map shows 12 sites for the species in the country. By 2020, the total number of finds has increased almost tenfold, up to about 120 . However, these include some observations in reconfirmed sites, or within the same localities. Most frequently fruitbodies of $S$. crispa were observed in Kyiv Region, including Kyiv city surroundings, in 2017-2020. Recent reports also represent first records in the territory of six more regions in the country: Chernivtsi, Chernihiv, Donetsk, Ivano-Frankivsk, Khmelnytskyi, and Zhytomyr regions.

\section{Distribution in Ukraine}

Autonomous Republic of Crimea: Alushta municipality, Crimean Nature Reserve, bank of the river Kacha, autumn 1936, S. Gutsevich (Sarkina et al., 2003); Yalta municipality, Yalta Mountain Forest Nature Reserve, Simeiz; 21.10.1987, V. Isikov; ibid., to southwest of Karagol lake, 07.10.1999, I. Sarkina (Sarkina et al., 2003).

Chernihiv Region: Chernihiv city, 12.09.2020, H. Sydorko; Bobrovytsia District, 06.10.2020, O. Skorokhod; Chernihiv District, Andriivka village, 12.09.2020, L. Radkovska; Kozelets District, Desna settlement, 18.08.2019, A. Skrypka; Mensk District, Makoshyne settlement, 19.10.2018, V. Bay.

Chernivtsi Region: Vyzhnytsia District, Myhove village, 01.09.2020, O. Kruhliy.

Donetsk Region: Donetsk city (Sukhomlyn, 2010).

Ivano-Frankivsk Region: Kosiv District, Hutsulshchyna National Nature Park (Bazyuk-Dubey, 2010).

Khmelnytskyi Region: Male Polissya National Nature Park, 09.10.2017, N. Kratasyuk; Shepetivka District, 28.10.2020, M. Bartoshchuk; Shepetivka town, 25.08.2020, R. Makarov. 
Kyiv city: 18.10.2020, P. Karakay; 18.09.2020, L. Zinevych; 28.09.2020, O. Zykov; Desniansky District, Bykivnia Forest, 12.10.2017, Yu. Bykova; ibid., 13.06.2019, O. Opanasyuk; power plant №6, 01.10.2018, I. Nechyporenko; Holosiiv District, Koncha-Zaspa, 21.09.2017, Z. Berest; ibid., 12.10.2017, L. Kapshuchenko-Pylypchuk; Obolon District, PushchaVodytsia, 30.09.1970, L. Horovyi (KW-M2150); ibid., 01.10.2009, G. Dryhus (KW-M36427) (Dzhagan et al., 2010); ibid., 11.09.2017, O. Dytynenko; ibid., 10.10.2017, N. Kosynska-Honcharuk; ibid., 22.10.2017, Ye. Rudenko; ibid., 16.11.2017, V. Bogdanov; Mezhyhirya forestry, 08.10.2017, Ye. Rudenko; Dnipro water supply station (Vodohin), 21.10.2017, M. Bakumenko; ibid., October 2018, O. Frusevych; near Redkine lake (Ministerske lake), 30.07.2019, T. Vashkulat; Podilskyi District, Vynohradar, 30.09.2018, O. Stadnyuk; Svyatoshyn District, Novobilychi, V. Heluta; ibid., 24.08.2018, I. Yarchuk; ibid., near Romanivka village, 30.09.2018, O. Kalaydzhi.

Kyiv Region: Borodyanka District, KlavdievoTarasove settlement, 04.10.2019, S. Belyavsky; Piskivka village (Red Data..., 2009); ibid., 06.10.2018, 31.10.2020, A. Akulenko; Nemishaeve settlement, 02.09.2018, G. Molnar; Potashnya village, 13.11.2010, V. Heluta ; ibid., 22.10.2011, V. Heluta; Boryspil District, Hnidyn village, 24.09.2017, N. Serha; Voronkiv village, 21.09.2020, N. Dan; Brovary District, 22.10.2020, T. Ulanova; Brovary town, 13.09.2011, O. Zykov; ibid., 16.10.2017, E. Anatskyi; ibid., 01.11.2018, O. Zynych; ibid., 29.09.2018, N. Zledenna; Zazymia village, 23.09.2017, A. Hladka; ibid., 29.09.2018, N. Zledenna; Fastiv District, Motovylivka railway station, 2018, V. Karnakova; Irpin municipality, Vorzel settlement, 07.10.2020, N. Safina; Ivankiv District, Rozvazhiv village, 13.10.2019, O. Fostenko; Stanishivka village, 13.10.2019, O. Khlobystov; Kyiv-Svyatoshynski District, Boyarka, 12.09.2020, S. Trofimenko; Khotiv village, 02.10.2018, O. Pashchenko; Moshchun village, 30.09.2017, V. Moiseyenko; Gorbovychi village, 16.10.2017, O. Aleksikova; between Khodosivka and Lisnyky villages, 04.11.2017, M. Rusin; Maliutyanka village, 13.11.2017, Y. Sichkarenko; Makariv District, Komarivka village, 16.09.2017, A. Mazur; ibid., 19.10.2017,V.Hnatenko;ibid.,05.10.2018,I.Kravchenko; Polissya District, Romanivka village, 30.09.2018, O. Kalaydzhi; Vasylkiv District, Vasylkiv town, 16.10.2008; Danylivka village, 05.11.2019, K. Yurchenko; Dzvinkove village, 14.10.2020, O. Romanenko; Zdorivka village, 29.08.2020, M. Shevchenko; Vyshhorod District, 29.10.2020, O. Stepanov; ibid., 11.09.2020,
R. Kochuba; ibid., 08.11.2020, O. Komarovskyi; Dymer settlement, 03.11.2018, K. Klyueva; Kruhy village, 07.10.2017, I. Ivanova; Lyutizh village, 10.09.2017, O. Hanych; ibid., 11.11.2017, 30.09.2018, O. Kubatchenko; ibid., 30.09.2018, Ye. Rudenko; Katyuzhanka village, 03.11.2018, K. Klyueva.

Lviv Region: Lviv city, 22.09.2018, I. Bulyak; ibid., 10.08.2019, A. Makaryk; Pustomyty District, Derevach village, 05.10.1969 (Dudka, 2008); Skole District, near Trukhaniv village, 29.08.2020, anonymous (on spruce tree); Sokal District, Borove village, 27.10.2017, V. Bilas; ibid., 09.09.2018, V. Bortnyk; Horbkiv village, 04.11.2019, V. Rudenko; Staryi Sambir District, Katyna village, 27.08.2020, O. Derkach; Stryi District, Semyhyniv village, 29.09.2018, V. Fal; Yavoriv District, Ivano-Frankove settlement, 16.09.1998 (Baziuk, 2000); Seredkevychi village, 06.10.2019, V. Basaraba; Verbliany village, 15.10.2016, N. Deshchytsia; Vereshchytsya village, 14.10.2019, B. Horin; Zhovkva District, Dobrosyn village, 03.09.2017, H. Markelov.

Rivne Region: Dubrovytsia District, Dubrovytsia forestry, 11.09.1953, V. Solomakhina (Solomakhina, 1956, 1957); Ostroh District, Viliya village, 17.09.2017, A. Hulko; Mezhyrich village, September 2018, O. Holovko; Radyvyliv District, Soloniv village, 06.10.2019, V. Tkachuk; Sarny District, Chabel village, 30.09.2018, M. Melnyk; Volodymyrets District, Rafalivka settlement, 30.09.2018, O. Shatkovska.

Transcarpathian Region: Rakhiv District, Carpathian Biosphere Reserve, Marmarosh massif (Gleb et al., 2016); Kostylivka village, Pip Ivan mountain, August 1936 (Pilát, 1940); Berlebash station, August 1937 (Pilát, 1940).

Volyn Region: Kamin-Kashyrskyi District, Klitytsk village, 20.10.2018, A. Parkhomchuk; Yalovatsk village, 24.10.2019, V. Ilchenko; Kivertsi District, Muravyshche village, early September 2004, O.P. Kurinchuk (Kurinchuk, 2005); Vesnyanka village, 17.09.2017, 29.09.2018, Yu. Prokopyuk; Lutsk District, Harasdzha village, 08.09.2016, V. Revnyuk; Manevychi District, Kolodii village, 06.09.2020, R. Hordiyevych; Pidhattya village, 13.09.2017, A. Voronyuk; Shatsk District, Shatsky National Nature Park, Svityaz village, 17.10.2018, K. Prasyuk; Vilshanka village, 24.10.2020, A. Klymyuk.

Zhytomyr Region: Malyn District, Zabrane village, 16.09.2017, S. Stepanyuk; Radomyshl District, 11.10.2020, A. Plyha; Zhytomyr District, Tryhirya village, 19.11.2017, 08.09.2018, V. Yakymchuk; ibid., 13.09.2018, T. Volodina. 


\section{Discussion}

Since recently, a great opportunity to improve the information on fungal occurrence has been provided via mushroom citizen science, i.e. involvement of volunteers in collecting distribution data for macrofungi, particularly those having large, easily observed fruitbodies. Recent advances in digital technologies, viz. high-resolution photography, and in social networking services have facilitated public participation in mycological observations through social media, such as Facebook specialized groups and other platforms.

The past decade has seen a rapid increase in citizen science initiatives for collecting large-scale data on fungal diversity, including occurrence data for woodinhabiting fungi (Heilmann-Clausen et al., 2016, 2019, and references therein). Various informal interest groups and citizen science projects guided by professional mycologists have appeared on the Internet in many countries in Europe and beyond, e.g. Danish Fungal Atlas (http://www.svampeatlas.dk, https://svampe.databasen. org), Finnish Fungal Atlas (http://sieniatlas.fi), The Lost and Found Fungi Project in the UK (https://www.kew. org/science/engage/get-involved/citizen-science/lostand-found-fungi), Mushroom Finder in Austria (https:// www.univie.ac.at/oemykges/pilzfinder-at/), Fungal Diversity Survey in North America (https://fundis. org/), Fungimap Australia (https://www.inaturalist.org/ projects/fungimap-australia), etc. Field documentation contributed by amateurs during these projects has notably increased scientific knowledge on fungal diversity, habitat and substrate data as well as public awareness of fungal conservation.

The reported species of aphyllophoroid fungi are confined either to old-growth forests (C. pistillaris, G. clavatus, H. coralloides, P. umbellatus, and S. crispa), or to steppe communities ( $P$. rhizophilus). Due to continuous degradation of such habitats, these rare fungi are threatened from habitat loss and are legally protected in Ukraine. Until recently, there was still a significant lack of knowledge on their occurrence across the country. However, in recent years, as it is shown in this study, compiled lists of their records have considerably extended, in particular for P. umbellatus, S. crispa, and H. coralloides.

A huge increase in observation data for fungi in Ukraine has also happened as a result of recent flow of the information publically available online. The studied six species of aphyllophoroid fungi produce large and distinctive polyporoid, or clavarioid, or gomphoid fruitbodies that usually cannot be overlooked. Overall views and close-up photographs of the observed fungi were taken by amateurs and uploaded to the Internet. These images have enabled professional mycologists, including the authors of this article, to verify reliable records and to compile datasets of the species distribution all over the country.

A great advantage of mushroom citizen science is collection of large amounts of data across large areas during a short optimal period for fungal fruiting that would be impossible otherwise. As a result, for some species a total number of records has increased exponentially. At the same time, almost all observations are located within the expected habitat ranges and thus fit into distribution patterns of the species. Likewise, a seemingly positive population trend does not reflect population growth, but rather fills the gaps in our knowledge on distribution of these fungi in the country.

Importantly, the compiled data serves as a considerably improved basis for future re-assessments of the Red List status of these fungi in Ukraine. On that basis, distribution maps will be produced and the species will be evaluated against the IUCN criteria for the next edition of the Red Data Book of Ukraine. Beyond that, information posted on social media is important for sharing and learning, and thus for enhancing public awareness of the protection of these threatened species of fungi. This is particularly true for P. umbellatus, S. crispa, and H. coralloides that otherwise would be likely picked up as edible fungi.

\section{Acknowledgements}

The authors thank all volunteers, whose names are listed in the reported observations, for providing additional data compiled in the article and photographs of the fungi.

This research was supported by the program "Support for development of priority areas of scientific research" (CPCEL 6541230). 


\section{References}

Akulov O.Yu., Leontyev D.V. 2008. Fungi listed in the Red Data Book of Ukraine from Homilshanski Lisy National Nature Park. Ukrainian Botanical Journal, 65(4): 586-589. [Акулов О.Ю., Леонтьєв Д.В. 2008. Гриби, занесені до Червоної книги України, з Національного природного парку "Гомільшанські ліси". Украӥнський ботанічний журнал, 65(4): 586-589].

Akulov O.Yu. 2016. In: The ecological, socio-economic and historical-cultural aspects of the Maramures border region development. Materials of the International scientific-practical conference. Khmelnytskyi, pp. 5-12. [Акулов О.Ю. 2016. Нові відомості про гриби Мармароського масиву Карпатського біосферного заповідника. В зб.: Екологічні, сочіально-економічні та історико-культурні аспекти розвитку прикордонних територій Мараморощчини. Матеріали Міжнародної науково-практичної конферениї (Рахів, 2-4 вересня 2016 р.). Хмельницький, с. 5-12].

Antosyak T.M., Kozurak A.V, Gleb R.Yu. 2019. In: Findings of plants and fungi listed in the Red Data Book of Ukraine and the Berne Convention (Resolution 6). Vol. 1 (Series: Conservation Biology in Ukraine, Issue 11). Kiev; Chernivtsi: Druk Art, pp. 9-13. [Антосяк T.M., Козурак А.В., Глеб Р.Ю. 2019. Знахідки рослин та грибів Червоної книги України, на території Карпатського біосферного заповідника. В кн.: Знахідки рослин і грибів Червоної книги та Бернської конвенції (Резолючія б). T. 1 (Серія: "Conservation Biology in Ukraine". Bun. 11). Ред. А.А. Куземко. Київ; Чернівці: Друк Арт, с. 9-13].

Babiychuk O.V. 2019. In: Findings of plants and fungi listed in the Red Data Book of Ukraine and the Berne Convention (Resolution 6). Vol. 1 (Series: Conservation Biology in Ukraine, Issue 11). Kiev; Chernivtsi: Druk Art, p. 14. [Бабійчук О.В. 2019. Знахідки рослин, занесених до Червоної книги України, на території Львівської та Волинської областей. В кн.: Знахідки рослин і грибів Червоної книги та Бернської конвениії (Резолюиія 6). T. 1 (Серія: "Conservation Biology in Ukraine". Bun. 11). Ред. А.А. Куземко. Київ; Чернівці: Друк Арт, с. 14].

Batochenko V.M. 2019. In: Findings of plants and fungi listed in the Red Data Book of Ukraine and the Berne Convention (Resolution 6). Vol. 1 (Series: Conservation Biology in Ukraine, Issue 11). Kiev; Chernivtsi: Druk Art, pp. 24-39]. [Баточенко В.М. 2019. Знахідки деяких видів флори, занесених до Червоної книги України, на ВолиноПоділлі та Закарпатті. В кн.: Знахідки рослин $і$ грибів Червоної книги та Бернської конвениії (Резолюиія б). Т. 1 (Серія: "Conservation Biology in Ukraine". Bun. 11). Ред. А.А. Куземко. Київ; Чернівці: Друк Арт, с. 24-39].

Baziuk I.V. 2000. Fungi species of the Red Data Book of Ukraine from the Ukrainian Roztochia. Ukrainian Botanical Journal, 57(2): 178-180. [Базюк I.B. 2000. Гриби Червоної книги України з Українського Розточчя. Украӥнський ботанічний журнал, 57(2): 178-180].

Bazyuk-Dubey I.V. 2010. Mycoflora of Hutsulshchyna National Nature Park. Scientific Bulletin of Ukrainian National Forestry University, 20(16): 118-128.
[Базюк-Дубей I.B. 2010. Мікофлора Національного природного парку "Гуцульщина". Науковий вісник Національного лісотехнічного університету Украӥни, 20(16): 118-128].

Bengus Yu.V. 2016. In: Rare plants and fungi of Ukraine and adjacent areas: implementing conservation strategies. Proceedings of the $4^{\text {th }}$ International conference. Kyiv, pp. 167-169. [Бенгус Ю.В. 2016. Нова знахідка Gomphus clavatus (Phallomycetidae, Agaricomycotina) в Українських Карпатах. В зб.: Рідкісні рослини $i$ гриби України та прилеглих територій: реалізачія природоохоронних стратегій. Матеріали IV міжнародної конференції (Київ, 16-20 травня 2016 р.). Київ, с. 167-169].

Bisko N.A., Lomberg M.L., Mytropolska N.Yu., Mykchaylova O.B. 2016. Kolektsiya kultur shapynkovykh hrybiv (IBK). Kyiv: Alterpress, 120 pp. [Бісько Н.A., Ломберг М.Л., Митропольська Н.Ю., Михайлова О.Б. 2016. Колекиія культур шапинкових грибів (IBK). Київ: Альтерпрес, 120 с.].

Bondartsev A.S. 1953. Trutovye griby evropeyskoy chasti SSSR $i$ Kavkaza. Moscow; Leningrad: Izd-vo AN SSSR, 1106 pp. [Бондарцев А.С. 1953. Трутовые грибы европейской части СССР и Кавказа. Москва; Ленинград: Изд-во АН СССР, 1106 с.].

Borščow E. 1869. Ein Beitrag zur Pilzflora der Provinz Černigow. Bulletin de l'Académie Impériale des Sciences de St. Pétersbourg, 13: 219-245.

Brusentsova N.O., Brusentsova O.V., Saidakhamedova N.B. 2019. In: Findings of plants and fungi listed in the Red Data Book of Ukraine and the Berne Convention (Resolution 6). Vol. 1 (Series: Conservation Biology in Ukraine, Issue 11). Kiev; Chernivtsi: Druk Art, pp. 84-88. [Брусенцова Н.О., Брусенцова О.В., Саідахмедова Н.Б. 2019. Види рослин і мікобіоти з Червоної книги України та Бернської конвенції на території Краснокутського району Харківської області. В кн.: Знахідки рослин i грибів Червоної книги та Бернської конвенції (Резолюиія 6). T. 1 (Серія: "Conservation Biology in Ukraine". Bun. 11). Ред. А.А. Куземко. Київ; Чернівці: Друк Арт, с. 84-88].

Dudka I.O. 2008. In: Pratsi Naukovoho tovarystva im. Shevchenka. Vol. 23: Ekolohichnyi zbirnyk. Lviv: Zakhidnyi naukovyi tsentr NAN Ukrainy i MON Ukrainy, pp. 48-62. [Дудка I.О. 2008. Колекція грибів Державного природознавчого музею НАНУ як джерело інформації про рідкісні та маловідомі види макроміцетів для включення їх до Червоної книги України. В кн.: Прачуі Наукового товариства ім. Шевченка. Т. 23: Екологічний збірник. Львів: Західний науковий центр НАН України і МОН України, с. 48-62].

Dzhagan V.V., Prydiuk M.P., Senchylo O.O. 2010. New records of macromycetes listed in the Red Data Book of Ukraine. Ukrainian Botanical Journal, 67(4): 587-595. [Джаган В.В., Придюк М.П., Сенчило О.О. 2010. Нові знахідки макроміцетів, занесених до "Червоної книги України". Український ботанічний журнал, 67(4): 587-595]. 
Fokshei S.I. 2016. Rare species of fungi in the old growth and virgin forests of Hutsulshchyna National Nature Park. Ukrainian Botanical Journal, 73(2): 72-77. [Фокшей C.I. 2016. Рідкісні види грибів у старовікових лісах i пралісах Національного природного парку "Гуцульщина". Український ботанічний журнал, 73(2): 72-77].

Fokshei S.I. 2019. In: Findings of plants and fungi listed in the Red Book of Ukraine and the Berne Convention (Resolution 6). Vol. 1 (Series: Conservation Biology in Ukraine, Issue 11). Kiev; Chernivtsi: DrukArt, pp. 426-430. [Фокшей C.I. 2019. Знахідки макроміцетів, занесених до Червоної книги України, в НПП "Гуцульщина". В кн.: Знахідки рослин і грибів Червоної книги та Бернської конвенції (Резолюиія б). T. 1 (Серія: "Conservation Biology in Ukraine". Bun. 11). Ред. А.А. Куземко. Київ; Чернівці: Друк Арт, с. 426-430].

Girzitska Z. 1929. Materialy do mikoflory Ukrainy. Visnyk Kyivskoho Botanichnoho Sadu, 10: 4-41. [Гіжицька 3.К. 1929. Матеріали до мікофлори України. Вісник Київського ботанічного саду, 10: 4-41].

Gleb R.Yu. 2016. In: The Plant Kingdom in the Red Data Book of Ukraine. Implementing the Global Strategy for Plant Conservation. Proceedings of the $3^{\text {th }}$ International Conference. Chernivtsi, pp. 313-315. [Глеб Р.Ю. 2016. Рідкісні види грибів Карпатського біосферного заповідника. У зб.: Регіональні аспекти флористичних $i$ фауністичних досліджень: матеріали третьої науково-практичної конферениії (13-14 травня 2016 р.). Чернівці, с. 313-315].

Gleb R.Y, Kapets N.V., Zykova M.O. 2016. In: The ecological, socio-economic and historical-cultural aspects of the Maramures border region development. Materials of the International scientific-practical conference. Khmelnytskyi, pp. 94-97. [Глеб Р.Ю., Капець Н.В., Зикова М.О. 2016. Рідкісні гриби Мармароського масиву Карпатського біосферного заповідника. В зб.: Екологічні, соціально-економічні та історикокультурні аспекти розвитку прикордонних територій Мараморощини. Матеріали Міжнародної науковопрактичної конферениії (Рахів, 2-4 вересня 2016 р.). Хмельницький, с. 94-97].

Hayova V.P., Heluta V.P., Shevchenko M.V. 2020. Fomitopsis officinalis (Polyporales): are there any records of the fungus known from Ukraine? Ukrainian Botanical Journal, 77(1): 40-43. https://doi.org/10.15407/ukrbotj77.01.040

Heilmann-Clausen J., Maruyama P.K., Bruun H., Dimitrov D., Laessøe T., Frøslev T., Dalsgaard B. 2016. Citizen science data reveal ecological, historical and evolutionary factors shaping interactions between woody hosts and wood-inhabiting fungi. New Phytologist, 212(4): 10721082. https://doi.org/10.1111/nph.14194

Heilmann-Clausen J., Bruun H.H., Ejrnæs R., Frøslev T.G., Læssøe T., Petersen J.H. 2019. How citizen science boosted primary knowledge on fungal biodiversity in Denmark. Biological Conservation, 237: 366-372. https:// doi.org/10.1016/j.biocon.2019.07.008

Isikov V.P. 2003. Macromycetes of woody plants of Crimea. Ukrainian Botanical Journal, 60(4): 447-463. [Ісіков В.П.
2003. Ксилотрофні макроміцети Криму. Украӥнський ботанічний журнал, 60(4): 447-463].

Karpenko K.K. 2004. New and rare for Ukraine species of macromycetes from the North-East part of the Left-Bank Forest-Steppe. Ukrainian Botanical Journal, 61(2): 34-40. [Карпенко К.К. 2004. Нові та рідкісні для України види макроміцетів із північно-східної частини Лівобережного Лісостепу. Украӥнський ботанічний журнал, 61(2): 34-40].

Karpenko K.K. 2009. Makromitsety zapovidnykh terytoriy Sumskoi oblasti. Sumy: PP Vinnychenko M.D., 356 pp. [Карпенко К.К. 2009. Макроміцети заповідних територій Сумської області. Суми: ПП Вінниченко М.Д., 356 с.].

Küffer N., Lovas P.S., Senn-Irlet B. 2004. Diversity of woodinhabiting fungi in natural beech forests in Transcarpathia (Ukraine): a preliminary survey. Mycologia Balcanica, 1: 129-134.

Kulsha Yu.M., Prudenko MM, Shevchyk V.L., Grishchenko V.M., Yablonska-Grishchenko Ye.D. 2019. In: Findings of plants and fungi listed in the Red Book of Ukraine and the Berne Convention (Resolution 6). Vol. 1 (Series: Conservation Biology in Ukraine, Issue 11). Kiev; Chernivtsi: Druk Art, pp. 270-271. [Кульша Ю.М., Пруденко М.М., Шевчик В.Л., Грищенко В.М., Яблонська-Грищенко Є.Д. 2019. Знахідки рідкісних видів грибів у Середньому Придніпров'ї у 20092018 pp. В кн.: Знахідки рослин і грибів Червоної книги та Бернської конвениії (Резолюція б). Т. 1 (Серія: "Conservation Biology in Ukraine". Bun. 11). Ред. А.А. Куземко. Київ; Чернівці: Друк Арт, с. 270-271].

Kurynchuk O.P. 2005. Sparasys kucheryavyi. Hryb, znaydenyi na Volyni vpershe. Zhyva Ukraina, 1-2: 20. [Куринчук О.П. 2005. Спарасис кучерявий. Гриб, знайдений на Волині вперше. Жива Україна, 1-2: 20].

Léveillé J.H. 1842. Observations médicales et enumeration des plantes recueillies en Tauride. In: Voyage dans la Russie méridionale et la Crimée, par la Hongrie, la Valachie et la Moldavie, exécuté en 1837, tome 2. Ed. A. Demidoff, E. Bourdin. Paris: Ernest Bourdin et Cie, pp. 34-242.

Malanyuk V.B. 2012. Hryby Chervonoi knyhy Ukrainy v obyektakh pryrodno-zapovidnoho fondu Karpatskoho rehionu. Naukovyi visnyk Natsionalnoho universytetu bioresursiv $i$ pryrodokorystuvannya Ukrainy, Seriya Lisivnytstvo ta dekoratyvne sadivnytstvo, 171(1): 124-127. [Маланюк В.Б. 2012. Гриби Червоної книги України в об'єктах природно-заповідного фонду Карпатського регіону. Науковий вісник Національного університету біоресурсів $і$ природокористування Украӥни. Сер.: Лісівниитво та декоративне садівничтво, 171(1): 124-127].

Malanyuk V.B. 2013. New records of macromycetes from the Red Data Book of Ukraine in Halych National Nature Park. Ukrainian Botanical Journal, 70(2): 251255. [Маланюк В.Б. 2013. Нові місцезнаходження занесених до "Червоної книги України" макроміцетів у Галицькому національному природному парку. Украӥнський ботанічний журнал, 70(2): 251-255]. 
Malanyuk V.B. 2019. In: Findings of plants and fungi listed in the Red Book of Ukraine and the Berne Convention (Resolution 6). Vol. 1 (Series: Conservation Biology in Ukraine, Issue 11). Kiev-Chernivtsi: Druk Art, pp. 285286. [Маланюк В.Б. 2019. Знахідки грибів Червоної книги України на території Івано-Франківської області. В кн.: Знахідки рослин і грибів Червоної книги та Бернської конвениії (Резолюиія б). T. 1 (Серія: "Conservation Biology in Ukraine". Bun. 11). Ред. А.А. Куземко. Київ; Чернівці: Друк Арт, с. 285-286].

Namysłowski B. 1914. Śluzowce i grzyby Galicyi i Bukowiny [Slime moulds and fungi of Galychyna and Bukovyna]. Pamętnik Fizyograficzny, 22(4): 1-151.

Petrichuk Yu., Pasaylyuk M. 2015. New records of the fungi listed in the Red Data Book of Ukraine from the Pokutski Carpathians. Ukrainian Botanical Journal, 72(4): 381-384. [Петричук Ю.В., Пасайлюк М.В. 2015. Нові місцезнаходження в Покутських Карпатах видів грибів, занесених до "Червоної книги України". Украӥнський ботанічний журнал, 72(4): 381-384].

Pilát A. 1940. Hymenomycetes Carpatorum orientalium. Acta Musei Nationalis Pragae, Series B, Historia Naturalis, 2(3): 37-80.

Prudenko M.M., Dzhagan V.V. 2008. A long-term monitoring of fungi in Kaniv Nature Reserve. Zapovidna Sprava $v$ Ukrayini, 14(2): 11-14. [Пруденко М.М., Джаган В.В. 2008. Багаторічний моніторинг грибів у Канівському заповіднику. Заповідна справа в Украӥні, 14(2): 11-14].

Prydiuk M.P. 2005. Bazydialni makromitsety Luhanskoho pryrodnoho zapovidnyka. Zbirnyk naukovykh prats Luhanskoho natsionalnoho ahrarnoho universytetu. Biolohichni nauky. Spetsialnyi vypusk, 56(79): 6992. [Придюк М.П. 2005. Базидіальні макроміцети Луганського природного заповідника. Збірник наукових праць Луганського національного аграрного університету. Біологічні науки. Спеціальний випуск, 56(79): 69-92].

Prylutsky O.V., Leontiev D.V., Bengus Yu.V. 2019. In: Findings of plants and fungi listed in the Red Book of Ukraine and the Berne Convention (Resolution 6). Vol. 1 (Series: Conservation Biology in Ukraine, Issue 11). Kiev; Chernivtsi: Druk Art, p. 324. [Прилуцький O.В., Леонтьєв Д.В., Бенгус Ю.В. 2019. Знахідки грибів 3 Червоної книги України на території Харківської області. В кн.: Знахідки рослин і грибів Червоної книги та Бернської конвениії (Резолючія б). Т. 1 (Серія: "Conservation Biology in Ukraine". Bun. 11). Ред. А.А. Куземко. Київ; Чернівці: Друк Арт, с. 324].

Red Data Book of Ukraine. Plant Kingdom. 2009. Ed. Ya.P. Didukh. Kyiv: Globalkonsaltyng, 912 pp. [Червона книга Укарїни. Рослинний світ. 2009. Ред. Я.П. Дідух. Київ: Глобалконсалтинг, 912 с.]

Rekita I.M. 2014. In: Pryrodnychi nauky: zbirnyk naukovykh prats. Vyp. 11. Sumy: SumDPU imeni A.S. Makarenka, pp. 25-33. [Рекіта I.M. 2014. Базидіомакроміцети лівобережжя p. Тересва в Тячівському районі Закарпатської області. В зб.: Природничі науки: збірник наукових працьь. Вип. 11. Суми: СумДПУ імені А. С. Макаренка, с. 25-33].
Sarkina I.S. 2004. Bazidialnye makromitsety stepnogo Kryma: Kerchenskiy poluostrov i Prisivashie. Sbornik nauchnykh trudov Gosudarstvennogo Nikitskogo botanicheskogo sada, 123: 50-58. [Саркина И.С. 2004. Базидиальные макромицеты степного Крыма: Керченский полуостров и Присивашье. Сборник научных трудов Государственного Никитского ботанического сада, 123: 50-58].

Sarkina I.S. 2008. In: Fundamentalnye i prikladnye problemy botaniki v nachale XXI veka: Materialy Vserossiyskoy konferentsii.Chast 2:algologiya,mikologiya, likhenologiya, briologiya. Petrozavodsk: Karelskiy nauchnyi tsentr RAN, pp. 159-162. [Саркина И.С. 2008. Микобиота заповедных территорий Крымского полуострова: макромицеты. В сб.: Фундаментальные и прикладные проблемь ботаники в начале XXI века: Материаль Всероссийской конференции (Петрозаводск, 22-27 сентября 2008 г.). Часть 2: альгология, микология, лихенология, бриология. Петрозаводск: Карельский научный центр РАН, с. 159-162].

Sarkina I.S., Mironova L.P. 2010. In: The Plant Kingdom in the Red Data Book of Ukraine. Implementing the Global Strategy for Plant Conservation. Proceedings of the International Conference. Kyiv, pp. 238-239. [Саркина И.С., Миронова Л.П. 2010. Макромицеты Карадагского природного заповедника (Крымский полуостров), занесенные в Красную книгу Украины. У зб.: Регіональні аспекти флористичних і фауністичних досліджень: матеріали міжнародної конференції (1115 жовтня 2010 р.). Київ, с. 238-239].

Sarkina I.S., Prydiuk M.P., Heluta V.P. 2003. Macromycetes of Crimea listed in the Red Data Book of Ukraine. Ukrainian Botanical Journal, 60(4): 438-446. [Саркіна I.C., Придюк М.П., Гелюта В.П. 2003. Макроміцети Криму, занесені до Червоної книги України. Украӥнський ботанічний журнал, 60(4): 438-446].

Shevchenko M.V., Heluta V.P, Hayova V.P. 2019. Distribution and conservation status of Grifola frondosa (Polyporales, Basidiomycota) in Ukraine. Ukrainian Botanical Journal 76(2): 144-151. https://doi.org/10.15407/ukrbotj76.02.144

Soldatova I.M. 1972. Novi ta malovidomi dlya URSR vydy afiloforoidykh hrybiv, vyyavleni $\mathrm{v}$ stepoviy zoni Ukrainskoi RSR. Ukrainian Botanical Journal, 29(4): 522-525. [Солдатова I.M. 1972. Нові та маловідомі для УРСР види афілофороїдих грибів, виявлені в степовій зоні Української РСР. Украӥнський ботанічний журнал, 29(4): 522-525].

Solomakhina V.M. 1956. In: Tezy dopovidey na XIII naukoviy sesii KDU. Kyiv, pp. 111-113. [Соломахіна В.M. 1956. Гриби - наземні макрофіти лісів Західного Полісся УРСР. У зб.: Тези доповідей на ХІІІ науковій сесї КДУ. Київ, с. 111-113].

Solomakhina V.M. 1957. Hrybni khvoroby stovburiv ta koreniv lisovykh derevnykh porid Zakhidnoho Polissya URSR. Naukovi zapysky Kyivskoho derzhavnoho universytetu, 20(14): 163-166. [Соломахіна В.М. 1957. Грибні хвороби стовбурів та коренів лісових деревних порід Західного Полісся УРСР. Наукові записки Київського державного університету, 20(14): 163-166]. 
Storozhenko Zh.V. 2019. In: Findings of plants and fungi listed in the Red Book of Ukraine and the Berne Convention (Resolution 6). Vol. 1 (Series: Conservation Biology in Ukraine, Issue 11). Kiev; Chernivtsi: Druk Art, pp. 343344. [Стороженко Ж.В. 2019. Знахідки рослин Червоної книги України на території НПП "Хотинський" та його околиць. В кн.: Знахідки рослин і грибів Червоної книги та Бернської конвениії (Резолючія б). Т. 1 (Серія: "Conservation Biology in Ukraine". Bun. 11). Ред. А.А. Куземко. Київ; Чернівці: Друк Арт, с. 343-344].

Sukhomlyn M.M. 2010. Kolektsiya hrybiv-makromitsetiv yak osnova stratehii zberezhennya henofondu bazydialnykh y askomitsetnykh hrybiv. Pryroda Zakhidnoho Polissya ta prylehlykh terytoriy, 7: 102-107. [Сухомлин М.M. 2010. Колекція грибів-макроміцетів як основа стратегії збереження генофонду базидіальних й аскоміцетних грибів. Природа Західного Полісся та прилеглих територій, 7: 102-107].

Taran N.A., Soldatova I.M., Wasser S.P. 1989. In: Biogeotsenologicheskie issledovaniya lesovtekhnogennykh landshaftov stepnoy Ukrainy. Dnepropetrovsk: DGU, pp. 58-73. [Таран Н.А., Солдатова И.М., Вассер С.П. 1989. Маркомицеты Присамарского леса. В кн.: Биогеоценологические исследования лесов техногенных ландшафтов степной Украины. Днепропетровск: ДГУ, с. 58-73].

Tyukh Yu.Yu., Niroda T.M. 2019. In: Findings of plants and fungi listed in the Red Book of Ukraine and the Berne Convention (Resolution 6). Vol. 1 (Series: Conservation Biology in Ukraine, Issue 11). Kiev; Chernivtsi: Druk Art, p. 382-383. [Тюх Ю.Ю., Нірода Т.М. 2019. Види рослин та грибів, включені до Червоної книги України, які знайдені за останні десять років на території НПП "Синевир". В кн.: Знахідки рослин і грибів Червоної книги та Бернської конвенції (Резолюція б). Т. 1 (Серія: "Conservation Biology in Ukraine". Bun. 11). Ред. А.А. Куземко. Київ; Чернівці: Друк Арт, с. 382-383].

Usichenko A.S., Akulov O.Yu., Ordynets A.V. 2005. In: Materialy mezhdunarodnoy nauchno-prakticheskoy konferentsii "Izuchenie i sokhranenie prirodnykh ekosistem zapovednikov lesostepnoy zony", posvyashchennoy 70-letiyu Tsentralno-Chernozemnogo zapovednika. Kursk, pp. 274-278. [Усиченко А.С., Акулов А.Ю., Ордынец А.В. 2005. Афиллофоровые грибы Каневского природного заповедника (Правобережная и Левобережная Лесостепь Украины). В зб.: Mатериаль международной научно-практической конферениии "Изучение и сохранение природных экосистем заповедников лесостепной зоны", посвященной 70-летию Центрально-Черноземного заповедника (пос. Заповедний, 22-26 мая 2005 г.). Курск, с. 274-278].
Usichenko A.S. 2011. Rare aphyllophoroid fungi from Homilshanski Lisy National Nature Park. Ukrainian Botanical Journal, 68(4): 570-580. [Усіченко А.С. 2011. Рідкісні види афілофороїдних грибів з Національного природного парку "Гомільшанські ліси" (Харківська обл.). Украӥнський ботанічний журнал, 68(4): 570-580].

Wasser S.P., Soldatova I.M. 1977. Vysshie bazidiomitsety stepnoy zony Ukrainy (Boletales, Agaricales, Russulales i Aphyllophorales). Kyiv: Naukova Dumka, 353 pp. [Вассер С.П., Солдатова И.М. 1977. Bысшие базидиомицеты степной зоны Украины (nор. Boletales, Agaricales, Russulales u Aphyllophorales). Киев: Наукова думка, 353 с. ].

Wróblewski A. 1922. Wykaz grzybów zebranych w latach 1913-1918 z Tatr, Pienin, Beskidów Wschodnich, Podkarpacia, Podola, Roztocza i innych miejscowości. I. Phycomycetes, Ustilaginaceae, Uredinales i Basidiomycetes. Sprawozdanie Komisji Fizjograficzney Polskiej Akademii Umiejętności, 55-56: 1-50.

Yurechko R.Yu. 2019. In: Findings of plants and fungi listed in the Red Book of Ukraine and the Berne Convention (Resolution 6). Vol. 1 (Series: Conservation Biology in Ukraine, Issue 11). Kiev; Chernivtsi: Druk Art, pp. 459-468. [Юречко Р.Ю. 2019.Знахідки рідкісних видів рослин у межах Львівської та Тернопільської областей. В кн.: Знахідки рослин $і$ грибів Червоної книги та Бернської конвенції (Резолюція б). Т. 1 (Серія: "Conservation Biology in Ukraine". Bun. 11). Ред. А.А. Куземко. Київ; Чернівці: Друк Арт, с. 459-468].

Zerova M.Ya. 1956. Nazemni hryby tsilynnykh stepiv Ukrainskoi RSR. Ukrainian Botanical Journal, 13(2): 6877. [Зерова М.Я. 1956. Наземні гриби цілинних степів Української РСР. Український ботанічний журнал, 13(2): 68-77].

Zerova M.Ya. 1957. Polyporus rhizophilus (Pat.) Sacc. i Pleurotus eryngii Fr. ex DC. var. ferulae Lanzi - tsikavi dlya Ukrainskoi RSR vydy hrybiv, vyyavleni v tsilynnykh stepakh. Ukrainian Botanical Journal, 14(2): 69-71. [Зерова М.Я. 1957. Polyporus rhizophilus (Pat.) Sacc. i Pleurotus eryngii Fr. ex DC. var. ferulae Lanzi - цікаві для Української РСР види грибів, виявлені в цілинних степах. Украӥнський ботанічний журнал, 14(2): 69-71].

Zerova M.Ya., Radziyevsky G.G., Shevchenko S.V. 1972. Vyznachnyk Hrybiv Ukrainy, vol. 5, book 1. Kyiv: Naukova Dumka, 239 pp. [Зерова М.Я., Радзієвський Г.Г., Шевченко С.В. 1972. Визначник грибів Украӥни, т. 5, кн. 1. Київ: Наукова думка, 239 с.].

Recommended for publication by M.M. Sukhomlyn 
Шевченко М.В., Гелюта В.П., Зикова М.О., Гайова В.П. 2021. Сучасні дані про поширення видів афілофороїдних грибів, включених до Червоної книги України. Украӥнський ботанічний журнал, 78(1): 47-61 [In English].

Інститут ботаніки ім. М.Г. Холодного НАН України, вул. Терещенківська 2, Київ 01601, Україна

Реферат. У статті подано узагальнену інформацію про поширення в Україні шести видів рідкісних афілофороїдних грибів (Agaricomycetes, Basidiomycota), включених до Червоної книги України - Clavariadelphus pistillaris, Gomphus clavatus, Hericium coralloides, Picipes rhizophilus, Polyporus umbellatus i Sparassis crispa. Для цих видів наводиться загалом на території країни близько 500 місцезростань; із них понад 410 виявлено після виходу у світ третього видання "Червоної книги України" у 2009 р. Значна частина цієї інформації була надана мікологамиаматорами, залученими упродовж кількох останніх років до збору даних про поширення на території країни грибів із добре помітними плодовими тілами. У статті подано виключно перевірену фахівцями інформацію про трапляння шести зазначених видів грибів. Узагальнені дані про поширення цих видів, що перебувають під загрозою зникнення, будуть використані для оцінки їхнього природоохоронного статусу у наступному виданні "Червоної книги України".

Ключові слова: Gomphales, Polyporales, види під загрозою зникнення, мікологи-аматори, охорона грибів, поширення, Червона книга України 